\title{
Effects of cisatracurium in combination with ventilation on inflammatory factors and immune variations in sepsis rats
}

\author{
TONGYUN HE $^{1}$, JIANMEI TAO ${ }^{2}$, XINQIANG WANG $^{1}$ and XUENA WANG ${ }^{1}$ \\ Departments of ${ }^{1}$ Anesthesiology and ${ }^{2}$ Pharmacy, The First People's Hospital of Huzhou, \\ Huzhou, Zhejiang 313000, P.R. China
}

Received December 14, 2017; Accepted February 16, 2018

DOI: $10.3892 /$ etm.2018.5978

\begin{abstract}
The effects of cisatracurium in combination with ventilation on inflammatory factors and immune variations in sepsis rats were investigated. A total of 54 male Sprague-Dawley rats were selected and divided randomly into three groups: Sham group $(n=6)$, model group $(n=24)$ and experiment group $(n=24)$. Rats in the model and experiment groups underwent cecal ligation and puncture (CLP) for establishment of sepsis model. Rats in experiment group additionally received cisatracurium medication in combination with ventilation for treatment. At 6, 12 and $24 \mathrm{~h}$ after CLP, the levels of tumor necrosis factor (TNF)- $\alpha$, interleukin (IL)-1 $\beta$, IL- 6 and procalcitonin (PCT) in serum and the ratio of leukocyte to neutrophil in peripheral blood was also detected. Twenty-four hours later, the expression of high mobility group box 1 (HMGB1) in lung tissues and cluster of differentiation (CD) $4^{+}$and $\mathrm{CD}^{+}$in T-lymphocyte subsets were also detected, and the wet/dry (W/D) ratio of lung was measured. Compared with that in model group, the levels of inflammatory factors in the experiment group were significantly decreased, while the indicators in assays of cellular immunity were obviously elevated. Ratio of leukocyte to neutrophil in peripheral blood was significantly decreased after treatment. Cisatracurium in combination with ventilation can alleviate the inflammatory injury to organs in sepsis rats through inhibiting the inflammatory responses and regulating the immune functions, which manifests a new significance in guiding the clinical diagnosis and treatment.
\end{abstract}

\section{Introduction}

Sepsis is a systemic inflammatory response syndrome (SIRS) caused by various factors, like endotoxin, exotoxin, virus or

Correspondence to: Dr Xuena Wang,Department of Anesthesiology, The First People's Hospital of Huzhou, 158 Guangchanghou Road, Wuxing, Huzhou, Zhejiang 313000, P.R. China

E-mail: qapsi515@163.com

Key words: cisatracurium, ventilation, sepsis rat, inflammatory factors, immune variations parasitic infection. With progression of the disease, inflammatory factors can activate a powerful immune response, or even immune dysregulation, thereby giving rise to dysfunction in organs and organic damage, in which acute lung damage is the most frequent event (1). At the initial stage of inflammation, tumor necrosis factor (TNF)- $\alpha$ is the first released pro-inflammatory factor, and the persistent increase in interleukin (IL)-1 $\beta$ and IL-6 indicates poor prognosis of SIRS (2). Inflammatory responses at the late stage can activate the enormous secretion of high mobility group box 1 (HMGB1) in lung tissues by mononuclear macrophages (3). In recent years, procalcitonin (PCT) serves as an indicator with a high value in monitoring sepsis in clinical practice (4). The aim of the present study was to explore a new method for diagnosis and treatment of sepsis in clinical practice through observing the effects of cisatracurium in combination with ventilation on expression of the above inflammatory factors and variations in cellular immunity in sepsis rats.

\section{Materials and methods}

Experiment animals. A total of 54 healthy Sprague-Dawley male rats (10-14 weeks old) weighing between 250 and $300 \mathrm{~g}$ were purchased from the Shanghai SIPPR-Bk Lab Animal Co., Ltd. (Shanghai, China). The rats were housed in a temperature controlled room $\left(21 \pm 2^{\circ} \mathrm{C}\right)$ on a 12-h light/dark cycle, with lights coming on at 06:00 a.m. All rats had free access to water and food. Facilities housing the animals were AAALAC-accredited at the time of the study. This study was approved by the Animal Ethics Committee of The First People's Hospital of Huzhou Animal Center (Huzhou, China).

Modeling methods and experimental grouping. Sepsis models were prepared using cecal ligation and puncture (CLP) method (5). According to the random digit principle, rats were divided into three groups, i.e. sham group $(n=6)$, model group $(n=24)$ and experiment group $(n=24)$. Animals were prepared for experiment after $12 \mathrm{~h}$ of fasting. For rats in sham group, they underwent laparotomy, while those in experiment group and model group were used for model establishment through CLP methods followed by symptomatic support with normal saline. After surgery, symptoms, including decreased activities, somnolence, dyspnea and other symptoms, appeared in sequence suggested that models were successfully established. 
Table I. Comparison of the levels of inflammatory factors in serum at different time-points among three groups (mean \pm SD).

\begin{tabular}{lcccccc}
\hline Groups & Case & Time-point (h) & TNF- $\alpha(\mathrm{pg} / \mathrm{ml})$ & IL-1 $\beta(\mathrm{pg} / \mathrm{ml})$ & IL-6 (pg/ml) & PCT (ng/l) \\
\hline Sham & 6 & & $19.62 \pm 6.37$ & $17.96 \pm 4.98$ & $22.25 \pm 2.58$ & $48.31 \pm 2.14$ \\
Model & 8 & 6 & $65.49 \pm 4.55^{\mathrm{b}}$ & $36.31 \pm 6.57^{\mathrm{b}}$ & $69.04 \pm 3.09^{\mathrm{b}}$ & $368.45 \pm 29.66^{\mathrm{b}}$ \\
& 8 & 12 & $47.55 \pm 3.47^{\mathrm{b}}$ & $31.12 \pm 5.16^{\mathrm{a}}$ & $83.68 \pm 3.24^{\mathrm{b}}$ & $359.84 \pm 28.34^{\mathrm{b}}$ \\
& 8 & 24 & $30.93 \pm 3.61^{\mathrm{a}}$ & $24.01 \pm 6.85$ & $66.35 \pm 5.13^{\mathrm{b}}$ & $377.00 \pm 26.65^{\mathrm{b}}$ \\
Experiment & 8 & 6 & $36.74 \pm 5.37^{\mathrm{d}}$ & $26.82 \pm 6.48^{\mathrm{d}}$ & $52.87 \pm 4.54^{\mathrm{d}}$ & $231.33 \pm 31.45^{\mathrm{c}}$ \\
& 8 & 12 & $26.78 \pm 5.70^{\mathrm{c}}$ & $22.01 \pm 4.78^{\mathrm{c}}$ & $64.77 \pm 3.69^{\mathrm{d}}$ & $219.47 \pm 32.21^{\mathrm{c}}$ \\
& 8 & 24 & $20.83 \pm 2.96^{\mathrm{c}}$ & $20.88 \pm 6.02$ & $50.47 \pm 6.95^{\mathrm{c}}$ & $199.45 \pm 35.13^{\mathrm{c}}$ \\
\hline
\end{tabular}

${ }^{\mathrm{a}} \mathrm{P}<0.05$, or ${ }^{\mathrm{b}} \mathrm{P}<0.01$ compared with sham group; ${ }^{\mathrm{C}} \mathrm{P}<0.05$, or ${ }^{\mathrm{d}} \mathrm{P}<0.01$ compared with model group. TNF- $\alpha$, tumor necrosis factor alpha; IL- $1 \beta$, interleukin-1beta; IL-6, interleukin-6; PCT, procalcitonin; SD, standard deviation.

Table II. Comparison of HMGB1 levels and W/D ratios of lung tissues among three groups at $24 \mathrm{~h}(\mathrm{mean} \pm \mathrm{SD})$.

\begin{tabular}{lcccc}
\hline Detection indicators & Case & Sham group & Model group & Experiment group \\
\hline HMGB1 (pg/ml) & 8 & $41 \pm 36$ & $118 \pm 21^{\mathrm{a}}$ & $59 \pm 34^{\mathrm{b}}$ \\
W/D ratio of lung tissues & 8 & $4.2 \pm 0.6$ & $6.5 \pm 0.5^{\mathrm{a}}$ & $4.6 \pm 0.4^{\mathrm{b}}$ \\
\hline
\end{tabular}

${ }^{\mathrm{a}} \mathrm{P}<0.01$ compared with sham group; ${ }^{\mathrm{b}} \mathrm{P}<0.05$ compared with model group. HMGB1, high mobility group box 1; W/D, wet/dry; SD, standard deviation.

Meanwhile, rats in the experiment group received cisatracurium treatment and tracheotomy for mechanical ventilation using the AVEA ventilator (Vyaire Medical, Mettawa, IL, USA).

Detection indexes. At 6, 12 and $24 \mathrm{~h}$ after CLP, animals were anesthetized by pentobarbital sodium, respectively, and at each time-point, 6 animals were treated for blood collection through abdominal aorta followed by isolation of serum. Using a Synergy H1 microplate reader (BioTek Instruments, Inc., Winooski, VT, USA), levels of TNF- $\alpha$, IL-1 $\beta$, IL-6 and PCT were detected in serum at different time-points; $24 \mathrm{~h}$ later, HMGB1 expression and wet/dry (W/D) ratio of lung tissues were determined. Thereafter, $\mathrm{T}$ lymphocyte subsets, cluster of differentiation (CD) $4^{+}$and $\mathrm{CD}^{+}$in serum were detected using the Attune Flow Cytometer (Applied Biosystems, Foster City, CA, USA). Ratio of leukocyte to neutrophil in peripheral blood was also measured using 7600 Automatic Biochemical Analyzer (Hitachi, Tokyo, Japan). FinePointe ${ }^{\mathrm{TM}}$ NAM Non-invasive Pulmonary Function Analyzer for Animals (Buxco, Troy, NY, USA) was used to detect the values of forced expiratory volume in one second $\left(\mathrm{FEV}_{1}\right), \mathrm{FEV}_{1} /$ forced vital capacity $(\mathrm{FVC})$ and $\mathrm{FEV}_{1} \%$ (percent of $\mathrm{FEV}_{1}$ in expected value).

Statistical analysis. Data analysis was carried out using SPSS 19.0 software (IBM, Armonk, NY, USA). Measurement data were presented as mean \pm standard deviation, t-test was performed for pairwise comparison and analysis of variance was carried out for multi-group comparison. Pearson's correlation analysis was adopted for correlation analysis. A $\mathrm{P}<0.05$ was considered to indicate a statistically significant difference.

\section{Results}

Comparisons of levels of inflammatory factors in serum at different time-points. The results of this study indicated that the levels of TNF- $\alpha$, IL-1 $\beta$, IL- 6 and PCT in serum at $6 \mathrm{~h}$ after the model establishment in the model group were significantly higher than those in sham group. Significant differences were identified in comparisons of the levels of TNF- $\alpha$, IL- 6 and PCT in serum at 6, 12 and $24 \mathrm{~h}$ between experiment group and model group $(\mathrm{P}<0.01$, or $\mathrm{P}<0.05)$, and comparisons of IL-1 $\beta$ level in serum at 6 and $12 \mathrm{~h}$ between two groups also showed statistically significant differences $(\mathrm{P}<0.01$ or $\mathrm{P}<0.05$; Table I).

Expression of HMGB1 (inflammatory mediator in the late stage) and W/D ratio of lung tissues. At $24 \mathrm{~h}$, expression of HMGB1 and W/D ratio of lung tissues were determined, and the results revealed that the level of HMGB1 and W/D ratio in model group were significantly higher than those in sham group; at $24 \mathrm{~h}$ after CLP, HMGB1 levels and W/D ratio of experiment group and model group was $59 \pm 34 \mathrm{vs} .118 \pm 21 \mathrm{pg} / \mathrm{ml}$ and $4.6 \pm 0.4$ vs. $6.5 \pm 0.5$, respectively, indicating that treatment can alleviate the inflammatory status in lung of sepsis rats (Table II).

Comparison of the levels of $T$ lymphocyte subsets at $24 \mathrm{~h}$. In this study, the results indicated that the indicator levels of $\mathrm{T}$ lymphocyte subsets in rats of model group at $24 \mathrm{~h}$ after CLP were significantly lower than those in sham group, and the portions of $\mathrm{CD}^{+}$and $\mathrm{CD}^{+}$as well as $\mathrm{CD} 4^{+} / \mathrm{CD}^{+}$ratios in experiment group and model group were $39.98 \pm 3.37$ vs. $27.35 \pm 4.01 \%, 27.17 \pm 4.22$ vs. $21.81 \pm 3.26 \%$ and 
Table III. Comparison of the levels of T lymphocyte subsets at $24 \mathrm{~h}$ among groups (mean $\pm \mathrm{SD})$.

\begin{tabular}{lcccc}
\hline Groups & Case & $\mathrm{CD}^{+}(\%)$ & $\mathrm{CD}^{+}(\%)$ & $\mathrm{CD}^{+} / \mathrm{CD}^{+}$ \\
\hline Sham & 6 & $51.71 \pm 4.42$ & $29.80 \pm 3.75$ & $1.69 \pm 0.39$ \\
Model & 8 & $27.35 \pm 4.01^{\mathrm{a}}$ & $21.81 \pm 3.26^{\mathrm{a}}$ & $1.13 \pm 0.05^{\mathrm{a}}$ \\
Experiment & 8 & $39.98 \pm 3.37^{\mathrm{c}}$ & $27.17 \pm 4.22^{\mathrm{b}}$ & $1.42 \pm 0.29^{\mathrm{b}}$ \\
\hline
\end{tabular}

${ }^{\mathrm{a}} \mathrm{P}<0.01$ compared with sham group; ${ }^{\mathrm{b}} \mathrm{P}<0.05$, or ${ }^{\mathrm{C}} \mathrm{P}<0.01$ compared with model group; $\mathrm{SD}$, standard deviation.

Table IV. Comparison of the indicators for pulmonary functions among groups (mean $\pm \mathrm{SD}$ ).

\begin{tabular}{lccccc}
\hline Groups & Case & Time-point $(\mathrm{h})$ & $\mathrm{FEV}_{1}(\mathrm{l})$ & $\mathrm{FEV}_{1} / \mathrm{FVC}_{(\%)}$ & $\mathrm{FEV}_{1}(\%)$ \\
\hline Sham & 6 & & $1.66 \pm 0.51$ & $68.83 \pm 8.16$ & $70.45 \pm 7.89$ \\
Model & 8 & 6 & $1.14 \pm 0.54^{\mathrm{a}}$ & $52.69 \pm 10.11^{\mathrm{b}}$ & $48.28 \pm 10.88^{\mathrm{b}}$ \\
& 8 & 12 & $1.18 \pm 0.49^{\mathrm{b}}$ & $53.36 \pm 9.51^{\mathrm{b}}$ & $49.57 \pm 9.62^{\mathrm{b}}$ \\
& 8 & 24 & $1.29 \pm 0.55^{\mathrm{b}}$ & $55.12 \pm 9.16^{\mathrm{b}}$ & $50.66 \pm 7.97^{\mathrm{b}}$ \\
Experiment & 8 & 6 & $1.27 \pm 0.38^{\mathrm{c}}$ & $56.78 \pm 9.25$ & $51.18 \pm 9.66^{\mathrm{c}}$ \\
& 8 & 12 & $1.52 \pm 0.37^{\mathrm{c}}$ & $60.15 \pm 10.01^{\mathrm{c}}$ & $55.26 \pm 8.74^{\mathrm{c}}$ \\
& 8 & 24 & $1.58 \pm 0.44^{\mathrm{c}}$ & $65.18 \pm 8.25^{\mathrm{d}}$ & $61.85 \pm 9.75^{\mathrm{d}}$ \\
\hline
\end{tabular}

${ }^{\mathrm{a}} \mathrm{P}<0.05$, or ${ }^{\mathrm{b}} \mathrm{P}<0.01$ compared with sham group; ${ }^{\mathrm{c}} \mathrm{P}<0.05$, or ${ }^{\mathrm{d}} \mathrm{P}<0.01$ compared with model group. $\mathrm{FEV}_{1}$, forced expiratory volume in one second; FVC, forced vital capacity; SD, standard deviation.

Table V. Correlation analysis between inflammatory factors in serum and pulmonary functions in sepsis.

\begin{tabular}{|c|c|c|c|c|}
\hline Corresponding variable & vs. TNF- $\alpha$ (r) & vs. IL- $1 \beta$ (r) & vs. IL-6 (r) & vs. PCT (r) \\
\hline $\mathrm{FEV}_{1}(\mathrm{l})$ & $-1.01^{\mathrm{a}}$ & -0.41 & $-0.79^{a}$ & $-0.85^{\mathrm{a}}$ \\
\hline $\mathrm{FEV}_{1} / \mathrm{FVC}(\%)$ & $-0.81^{\mathrm{a}}$ & -0.40 & $-0.68^{a}$ & $-0.79^{\mathrm{a}}$ \\
\hline $\operatorname{FEV}_{1}(\%)$ & $-0.90^{\mathrm{a}}$ & -0.31 & $-0.74^{\mathrm{a}}$ & $-0.99^{\mathrm{a}}$ \\
\hline
\end{tabular}

${ }^{\mathrm{a}} \mathrm{P}<0.05 . \mathrm{FEV}_{1}$, forced expiratory volume in one second; $\mathrm{FVC}$, forced vital capacity; TNF- $\alpha$, tumor necrosis factor alpha; IL- $1 \beta$, interleukin- 1 beta; IL-6, interleukin-6; PCT, procalcitonin.

$1.42 \pm 0.29$ vs. $1.13 \pm 0.05 \mathrm{pg} / \mathrm{ml}$,respectively, suggesting that the immune functions of sepsis rats are ameliorated after treatment $(\mathrm{P}<0.01$, or $\mathrm{P}<0.05$; Table III $)$.

Comparison of the indicators for pulmonary functions. Results of this study suggested that at $24 \mathrm{~h}$ after model establishment, indicator levels for pulmonary functions of rats in model group were significantly lower than those in sham group, while the values of $\mathrm{FEV}_{1}, \mathrm{FEV}_{1} / \mathrm{FVC}$ and $\mathrm{FEV}_{1} \%$ at 6,12 and $24 \mathrm{~h}$ after CLP in model group were significantly lower than those in the experiment group, and the differences had statistical significance $(\mathrm{P}<0.01$ or $\mathrm{P}<0.05$; Table IV).

Correlation analysis between inflammatory factors in serum and pulmonary functions in sepsis. According to Pearson's correlation analysis, levels of TNF- $\alpha$, IL- 6 and PCT in sepsis were negatively correlated with the indicators for pulmonary functions, $\mathrm{FEV}_{1}, \mathrm{FEV}_{1} / \mathrm{FVC}$ and $\mathrm{FEV}_{1}(\%)$, and the correlation had statistical significance $(\mathrm{P}<0.05)$, suggesting that the level of inflammatory factors is directly correlated with the pulmonary function status (Table V).

Comparison of the ratio of leukocytes to neutrophils in peripheral blood of animals. The results of this study indicated that at $6 \mathrm{~h}$ after model establishment, ratio of leukocytes to neutrophils in peripheral blood in rats of model group was significantly higher than that in sham group, while after treatment, ratios in experiment group at different time-points were all higher than those in the model group $(\mathrm{P}<0.01$; Table VI).

\section{Discussion}

The major pathophysiological mechanism accounting for the development and progression of sepsis lies in the dysregulation of dynamic balance between inflammatory mediators and anti-inflammatory factors in SIRS (6). Infection, without timely treatment, usually leads to severe persistent hypotension, and affects the physiological functions of multiple organs 
Table VI. Comparison of the ratio of leukocyte to neutrophil in peripheral blood of animals among the groups (mean \pm SD).

\begin{tabular}{|c|c|c|c|c|}
\hline Groups & Case & Time-point (h) & Count of leukocytes $\left(\times 10^{9} / 1\right)$ & Ratio of leukocytes to neutrophils (\%) \\
\hline Sham & 6 & & $4.42 \pm 0.94$ & $63.11 \pm 0.23$ \\
\hline \multirow[t]{3}{*}{ Model } & 8 & 6 & $11.91 \pm 1.32^{\mathrm{a}}$ & $81.98 \pm 1.52^{\mathrm{a}}$ \\
\hline & 8 & 12 & $14.99 \pm 1.56^{\mathrm{a}}$ & $89.81 \pm 2.14^{\mathrm{a}}$ \\
\hline & 8 & 24 & $13.21 \pm 1.42^{\mathrm{a}}$ & $84.12 \pm 1.91^{\mathrm{a}}$ \\
\hline \multirow[t]{3}{*}{ Experiment } & 8 & 6 & $7.30 \pm 0.88^{\mathrm{b}}$ & $76.11 \pm 1.61^{\mathrm{b}}$ \\
\hline & 8 & 12 & $6.43 \pm 1.02^{\mathrm{c}}$ & $73.87 \pm 1.44^{\mathrm{c}}$ \\
\hline & 8 & 24 & $5.65 \pm 1.56^{\mathrm{c}}$ & $70.01 \pm 1.11^{\mathrm{c}}$ \\
\hline
\end{tabular}

${ }^{\mathrm{a}} \mathrm{P}<0.01$ compared with sham group; ${ }^{\mathrm{b}} \mathrm{P}<0.05$, or ${ }^{\mathrm{c}}<0.01$ compared with model group. $\mathrm{SD}$, standard deviation.

in the body, contributing to the septic shock and multiple organ dysfunction syndrome (MODS) that lead to death of almost $80 \%$ of sepsis patients $(7,8)$.

In the network of inflammatory cytokines, TNF- $\alpha$ is released first, and can activate downstream signal transduction pathway to induce the secretion of inflammatory cytokines (IL-1 $\beta$ and IL-6) through binding with the receptors, and inhibit the generation of anti-inflammatory factors, thereby giving rise to waterfall-like cascade reactions of inflammation (9). Sepsis is always accompaned by an acute increase in PCT. Generally, within 3 or $4 \mathrm{~h}$ after infection, PCT can be detected in the body, and peak level is usually attained within 8 to $24 \mathrm{~h}$. It has been confirmed that PCT can serve as an effective indicator for diagnosis of infection in critical patients to monitor the variations in conditions of sepsis, and an elevation in PCT can be identified in severe systemic infection and septic shock (10). Deng et al (11) proved that HMGB1 can induce the generation of inflammatory cytokines through activating the macrophages, thereby leading to the onset of acute lung injury (ALI). Bone, an American scholar, put forward the hypothesis of compensatory anti-inflammatory response syndrome (12), in which it was proposed that the imbalance between pro- and anti-inflammation mechanism leads to the development of sepsis, and to a certain degree, T lymphocyte subsets can induce the corresponding reactions specifically for the status of cellular immunity. In progression of SIRS, the role of immune system has also become a hotspot in clinical and fundamental research $(13,14) . \mathrm{CD}^{+} \mathrm{T}$ and $\mathrm{CD} 8^{+} \mathrm{T}$ are featured with the functions of antibody generation, activation of macrophages and regulation of cellular immunity. It is reported that a decrease in $\mathrm{CD}^{+}{ }^{+} \mathrm{T} / \mathrm{CD}^{+} \mathrm{T}$ ratio indicates that sepsis has evolved into a severe phage and the prognosis is poor (15). In clinical practice, mechanical ventilation has been usually considered to increase the oxygenation capacity, thereby ameliorating the pulmonary ventilation function and alleviating the inflammatory responses. Non-depolarizing muscle relaxants (atracurium as a common non-depolarizing muscle relaxant in clinical practice), major adjuvant drugs in mechanical ventilation of sepsis patients, can alleviate the inflammatory responses in airways (16). Narimatsu et al (17) reported that affected by the inflammatory mediation, in vivo expression of acetylcholine receptors in sepsis patients shows poor sensitivity to non-depolarizing muscle relaxant, leading to neuromuscular dysfunction, delay in initiation of effect and shortness of drug action. Cisatracurium is one of the geometric isomers, and according to the pharmacodynamics studies, its effect on muscular relaxation is almost three times that of atracurium (18). It is also reported that the other prominent feature of cisatracurium is rapid onset and metabolism but without release of histamine, a major endogenous active substance in allergic reaction $(19,20)$.

Results of this study indicated that at $6 \mathrm{~h}$ after the model establishment, levels of inflammatory factors in the model and the experiment groups were significantly higher than those in the sham group, suggested that models were successfully established. At 6, 12 and $24 \mathrm{~h}$ after treatment, decline was detected in levels of inflammatory factors, including TNF- $\alpha$, IL- 6 and PCT in the experiment group, which was significantly lower than those in model group at the same time-point. At 6 and $12 \mathrm{~h}$, differences in levels of IL-1 $\beta$ between two groups had statistical significance $(\mathrm{P}<0.01$ or $\mathrm{P}<0.05)$. At $24 \mathrm{~h}$, measurements of expression of HMGB1 and W/D ratio of lung tissues indicated: The level of HMGB1 and W/D ratio in model group was significantly higher than those in sham group; at $24 \mathrm{~h}$ after CLP, HMGB1 levels and W/D ratio in experiment group and model group was $59 \pm 34$ vs. $118 \pm 21 \mathrm{pg} / \mathrm{ml}$ and $4.6 \pm 0.4$ vs. $6.5 \pm 0.5$, respectively, suggesting that treatment can alleviate the pulmonary inflammation to a certain extent. Portions of $\mathrm{CD}^{+}$ and $\mathrm{CD}^{+}$as well as $\mathrm{CD}^{+} / \mathrm{CD}^{+}$ratio in experiment group and model group was $39.98 \pm 3.37$ vs. $27.35 \pm 4.01 \%, 27.17 \pm 4.22$ vs. $21.81 \pm 3.26 \%$, and $1.42 \pm 0.29$ vs. $1.13 \pm 0.05 \mathrm{pg} / \mathrm{ml}$, respectively, suggesting that the immune functions of sepsis rats are ameliorated after treatment $(\mathrm{P}<0.01$, or $\mathrm{P}<0.05)$. In addition, according to Pearson's correlation analysis, levels of TNF- $\alpha$, IL-6 and PCT in sepsis were negatively correlated with the indicators for pulmonary functions, $\mathrm{FEV}_{1}, \mathrm{FEV}_{1} / \mathrm{FVC}$ and $\mathrm{FEV}_{1}(\%)$, and the correlation had statistical significance $(\mathrm{P}<0.05)$, suggesting that the level of inflammatory factors is directly correlated with the pulmonary function status. After treatment, the count of leukocytes and its ratio to neutrophils in peripheral blood in the experiment group at different time-points were all higher than those in the model group. Thus, this study confirmed that cisatracurium in combination with ventilation can increase the cellular immune functions and combat the inhibitory effect on immune system produced in sepsis, but the specific mechanism requires further studies. 
In conclusion, cisatracurium in combination with ventilation can alleviate the inflammatory injury to organs in sepsis rats through inhibiting the inflammatory responses and regulating the immune functions, which manifests a new significance in guiding the clinical diagnosis and treatment.

\section{Acknowledgements}

Not applicable.

\section{Funding}

The present study was supported by the Singch Anesthesia Research Fund Aids (2015ZYC-A64).

\section{Availability of data and materials}

All data generated or analyzed during this study are included in this published article.

\section{Authors' contributions}

TH designed the study and performed the animal experiments, JT and XiW collected and analysed the data, TH prepared the manuscript, $\mathrm{XuW}$ contributed to establishing the animal model and collected the funds. All authors read and approved the final manuscript.

\section{Ethics approval and consent to participate}

This study was approved by the Animal Ethics Committee of The First People's Hospital of Huzhou Animal Center (Huzhou, China).

\section{Consent for publication}

Not applicable.

\section{Competing interests}

The authors declare that they have no competing interests.

\section{References}

1. Fuller BM, Mohr NM, Dettmer M, Kennedy S, Cullison K, Bavolek R, Rathert N and McCammon C: Mechanical ventilation and acute lung injury in emergency department patients with severe sepsis and septic shock: An observational study. Acad Emerg Med 20: 659-669, 2013.

2. Kim GY, Roh SI, Park SK, Ahn SC, Oh YH, Lee JD and Park YM: Alleviation of experimental septic shock in mice by acidic polysaccharide isolated from the medicinal mushroom Phellinus linteus. Biol Pharm Bull 26: 1418-1423, 2003.
3. Thomas JO: HMG1 and 2: Architectural DNA-binding proteins. Biochem Soc Trans 29: 395-401, 2001.

4. Standage SW and Wong HR: Biomarkers for pediatric sepsis and septic shock. Expert Rev Anti Infect Ther 9: 71-79, 2011.

5. Singleton KD and Wischmeyer PE: Distance of cecum ligated influences mortality, tumor necrosis factor-alpha and interleukin-6 expression following cecal ligation and puncture in the rat. Eur Surg Res 35: 486-491, 2003.

6. Delong P, Murray JA and Cook CK: Mechanical ventilation in the management of acute respiratory distress syndrome. Semin Dial 19: 517-524, 2006.

7. Galley HF: Oxidative stress and mitochondrial dysfunction in sepsis. Br J Anaesth 107: 57-64, 2011.

8. Wang YT, Fu JJ, Li XL, Li YR, Li CF and Zhou CY: Effects of hemodialysis and hemoperfusion on inflammatory factors and nuclear transcription factors in peripheral blood cell of multiple organ dysfunction syndrome. Eur Rev Med Pharmacol Sci 20: 745-750, 2016.

9. Xie C, Kang J, Ferguson ME, Nagarajan S, Badger TM and Wu X: Blueberries reduce pro-inflammatory cytokine TNF- $\alpha$ and IL- 6 production in mouse macrophages by inhibiting NF- $\kappa B$ activation and the MAPK pathway. Mol Nutr Food Res 55: 1587-1591, 2011.

10. Jain S, Sinha S, Sharma SK, Samantaray JC, Aggrawal P, Vikram NK, Biswas A, Sood S, Goel M, Das M, et al: Procalcitonin as a prognostic marker for sepsis: A prospective observational study. BMC Res Notes 7: 458, 2014.

11. Deng Y, Yang Z, Gao Y, Xu H, Zheng B, Jiang M, Xu J, He Z and Wang X: Toll-like receptor 4 mediates acute lung injury induced by high mobility group box-1. PLoS One 8: e64375, 2013.

12. Rittirsch D, Huber-Lang MS, Flierl MA and Ward PA: Immunodesign of experimental sepsis by cecal ligation and puncture. Nat Protoc 4: 31-36, 2009.

13. Janeway CA Jr and Medzhitov R: Innate immune recognition. Annu Rev Immunol 20: 197-216, 2002.

14. Ackland G, Grocott MP and Mythen MG: Understanding gastrointestinal perfusion in critical care: So near, and yet so far. Crit Care 4: 269-281, 2000.

15. Ohsugi T and Kumasaka T: Low CD4/CD8 T-cell ratio associated with inflammatory arthropathy in human T-cell leukemia virus type I Tax transgenic mice. PLoS One 6: e18518, 2011.

16. Yamada M, Buller R, Bledsoe S and Storch GA: Rising rates of macrolide-resistant Mycoplasma pneumoniae in the central United States. Pediatr Infect Dis J 31: 409-400, 2012.

17. Narimatsu E, Niiya T, Kawamata M and Namiki A: Sepsis stage dependently and differentially attenuates the effects of nondepolarizing neuromuscular blockers on the rat diaphragm in vitro. Anesth Analg 100: 823-829, 2005.

18. Lu A, Wang L, Zhang X and Zhang M: Combined treatment for child refractory mycoplasma pneumoniae pneumonia with ciprofloxacin and glucocorticoid. Pediatr Pulmonol 46: 1093-1097, 2011.

19. Hong SJ: The role of mycoplasma pneumoniae infection in asthma. Allergy Asthma Immunol Res 4: 59-61, 2012.

20. Miksa M, Wu R, Zhou M and Wang P: Sympathetic excitotoxicity in sepsis: Pro-inflammatory priming of macrophages by norepinephrine. Front Biosci 10: 2217-2229, 2005.

This work is licensed under a Creative Commons Attribution-NonCommercial-NoDerivatives 4.0 International (CC BY-NC-ND 4.0) License. 